\title{
Why do people want currency? Institutions, habit, and bricolage in an Argentine marketplace
}

\section{Georgina M. Gómez ${ }^{1}$ [D}

Published online: 15 October 2018

(c) The Author(s) 2018

\begin{abstract}
While initiatives in the social economy keep multiplying, the theoretical foundations for their research need further development; there is minimal reflection on the "institutional innovation" that these schemes promote. The study adopts an evolutionary approach to discuss the roles of habit, institutions, and bricolage in the organisation of new economic schemes. The research is grounded on the case of a complementary currency system designed by a small group of low-income vendors in a weekend marketplace in Buenos Aires, Argentina. It was implemented to facilitate exchanges of goods in anticipation of the Christmas of 2012. Given the small size of the group, their high level of social cohesion, and their shared experiences with monetary plurality, they could have implemented simpler exchange systems such as direct barter or a non-perishable divisible commodity as general equivalent. In contrast, the vendors collectively decided they wanted their own currency with physical notes, a reserve, and a treasurer. The research is guided by the question of what made the group determined to configure their own currency. It contends that the shared habits of the vendors and the monetary institutions in Argentina, which include monetary plurality, supported a process of bricolage that drove to the institutional innovation of a marketplace currency.
\end{abstract}

Keywords Complementary currency systems · Institutional innovation · Evolutionary economics $\cdot$ Informal vendors $\cdot$ Trueque $\cdot$ Argentina

JEL Classification B5 $\cdot \mathrm{O} 3 \cdot \mathrm{R} 1 \cdot \mathrm{G} 0$

Georgina M. Gómez

gomez@iss.nl

1 International Institute of Social Studies, Erasmus University Rotterdam, Rotterdam,

Zuid Holland, The Netherlands 


\section{Introduction}

A group of vendors in a weekend market in a square in Buenos Aires, Argentina introduced a system of own currency to be used 1 day near the Christmas 2012. The vendors produced home-made items, such as preserved foods and pastries, handicrafts, artisanal toiletries, and so on. They were barely managing to make ends meet with their sales, and with Christmas approaching, they were thinking of ways to obtain Christmas gifts for their friends and relatives with the scarce income that they were making. They recalled positive experiences with the complementary currency systems that thrived between 1995 and 2003, the Redes de Trueque (Gomez 2009, 2010), and some starting wondering how they could reinstate these complementary currencies. At the same time, some of the vendors were negatively affected by the demise of the Redes de Trueque, so they were reluctant to join in a similar scheme unless sufficient corrections could be made. The idea was implemented with 22 vendors in December 2012 and collectively allowed them to trade almost 2.5 times the value of the currency in circulation. The participants were satisfied with the result and the currency was burnt at the end of the day in a festive event meant to show how easy paper money can be made and unmade by a social group.

The mainstream version (for example, Menger 1892; Samuelson 1967) on why money emerged as a key economic institution focuses on its efficiency advantage. It states that money reduces the transaction costs of bartering and allows values to be transferred across time and space (Hodgson 2004; Ingham 2002). However, the case study on which this research is based discloses that these motives could not has appealed the vendors. As soon as the supporting team started discussions with the interested ones, we found out that they were a group of 30 people that have known each other for years. We observed high levels of personal trust and social cohesion among the many diverse opinions, which we considered as preconditions for a functioning social system and for the implementation of a complementary currency (Krabbe 2015). Such traits reflected in a history of collective action, as the vendors organised the market together, negotiated the space with the municipality, and set a number of rules which they managed to enforce horizontally. The vendors made it clear that they needed means of payment to exchange goods for Christmas and did not wish to create a complementary currency system beyond that. Therefore, there was no need to create a system that allowed them to transfer value across time and space and an accountancy system could have solved the problem of the double coincide of needs typical of barter. Still, the vendors were determined to have a complementary currency with physical notes. The support team also explained to the vendors that they could adopt a non-perishable and easily divisible commodity as general equivalent, which scholars such as Adam Smith (1991 [1776]) identify as the origins of money. Instead, the vendors wanted paper money and the puzzle motivated the research question in this article: why do people want a physical currency?

The market is the basis of the current study, which seeks to reflect on the nature of institutional innovation within the social and solidarity economy. The artisans asked for the support of experts to design and implement a complementary currency system that would facilitate trade in their market square. Such support was given by 
the author, municipal social workers, and assistants who kept records of the experience and which became the source of the present research. The supporting team on the ground consulted me throughout the initiative and shared their records that source the data for this article. The data of the case study were collected with a participatory ethnographic method, so while we kept systematic records of every meeting, we were also actively participating in the discussions and making suggestions. In addition, a short questionnaire was distributed to the participants before and after the experience with the goal of defining the profile of the participants and the impact of the experiment. The names used in this study are pseudonyms. We called the vendors' currency the "money for a day" initiative, because it was a currency that the vendors used to trade with each other and expired at the end of 1 day.

The article will first account for the details of the experiment and will analyse the various alternatives that the supporting team discussed with the vendors. It will then present an institutional analysis of the initiative, as described in Sect. 4. The article will argue that the use of money for trade stems from the habit (Veblen 1899) of using money and designing local money, and the choice reveals little of their reflections on transaction costs and efficiency. Veblen's definition of habits of thought refers to the engrained practices that make individuals and groups almost incapable of engaging with alternative options. The study contends that the "institutional innovation" at the grassroots level presents a process of bricolage (Cleaver 2002; Levi Strauss 1962) based on elements of an established institutional structure that are adapted and recombined to fit the contingencies and contexts of groups, which leads to new institutions. In the approach of this research paper, the cumulative process of adapting, innovating, and creating institutions is evolutionary, because it sustains additional patterns of social interactions. These are "institutional facts" that depend on existent institutions on which future institutions are configured (Searle 1995, 2005). They become the "common knowledge" of a population that differs from that of the past and of other populations (Lewis 2008 \{1996\}: 78).

\section{The situation of the vendors}

The vendors relied on several years of trading in the same place and had repeatedly organised events to increase sales. The average age was estimated at 48 and the average educational attainment was 11.5 years, equivalent to complete primary education and incomplete secondary education in Argentina. They had a similar common language among them and a shared middle-class past that was lost when they became unemployed, bankrupt or faced various personal and family calamities during the structural adjustment and economic crisis of 1998-2002. They turned to manufacturing artisanal products at home with flexible hours and small capital that they could sell in their networks and in the open-air weekend market, where this research is located. They sometimes had other odd jobs and shared the view that "with a little income from here and there we can manage", as one of them expressed it (Interviewee A, 1/12/2012). They thought of themselves as micro-entrepreneurs 
and mostly had the capacity to produce more, but they considered that there was insufficient demand to justify an expansion.

Among the rules, they had decided collectively, the participants mentioned the opening times, the contribution of fees for cleaning and illumination, and the prohibition of items on sale that they had not produced themselves. These rules were discussed for some time and once agreed upon the participants regarded them highly for the maintenance of their social order, which derived in high compliance. Transgressions were dealt with collectively, and behaviour was usually corrected via social control mechanisms. Additional vendors were added gradually and were usually known by some the existent participants.

The vendors' weekend sales were too low for them to afford extra expenses such as Christmas presents. Facing the same situation, five of the vendors had organised a barter experience 1 year earlier, in which they exchanged their products to have Christmas presents for families and relatives. They were so satisfied with the experience that they wanted to repeat it and expand it in scale and scope, with more participants and a broader choice of products on offer. However, more variety of products meant a more diverse range of values, such as hand-knit pullovers, scarfs, toiletries, and candles. They thought they needed a more sophisticated exchange system, so two vendors visited a social worker they knew to see if they had any suggestions. The social worker was a public servant in the municipality and contacted them with a sociologist and a researcher on local currency systems. In this way, a "support team" of experts was formed.

The result of these contacts was to call a general meeting to summon interested participants after the trading hours in the open market. On the day selected, 15 entrepreneurs stayed (11 women and 4 men) and the meeting took place under the trees. The initial discussion referred to the role of money, what creates inflation, the function of banks and the importance of foreign currency as collateral, which evidenced that the financial knowledge of the entrepreneurs was informed by popular media. At the same time, all the vendors had been active in the Redes de Trueque, the complementary currency system that allowed 2.5 million Argentines to go by in the crisis of 1998-2002 (Gomez 2009, 2010). The vendors shared their experiences in the Trueque, what they did, and how it improved their lives until its demise. For their new experience, they wanted to create a currency as means of payment "as it was done in the Trueque" (Interviewee B, 21/11/2012). There was a certain consensus that with means of payment, they would be able to make the exchanges "more transparent", detaching transactions from their personal relationships and generally making sure that "nobody loses" (Interviewee C, 8/12/2012).

They subsequently discussed the experience of bartering 1 year earlier and how they dealt with the problem of the double coincidence of wants. This problem is referred by several scholars (Menger 1892; Peacock 2012) as the main explanation for the replacement of direct bartering by money and addresses the difficulty of finding an immediate direct buyer and seller of two goods of equal value. It contends that a general divisible equivalent as means of payment reduces transaction costs (Jevons 1875). In that line, Melitz $(1974,77)$ defined money as "all goods that are held in significant measure to economise on transaction costs in the activity of trading a variety of other types of goods". The vendors in our case study recognised the 
problem, but did not consider it a critical issue, because in the previous year, they could adjust quantities in such a way that they managed the values and exchanges took place. Their desire to use currency responded to the hope of making the system easier and more attractive, so it would attract more participants and a broader choice of products. Moreover, they repeated several times that currency was what "everyone is used to" (Interviewee C, 8/12/2012), while barter demanded an extra effort and more trust. The main advantage of currency, they claimed, was "making it easier to fix and compare prices and keep trade honest" (Interviewee E, 1/12/2012). The critical issue, they repeated, was about transparency in fixing prices without having to argue or feel that the exchange was unfair for one of the trading parts.

The support team understood that the vendors were emphasising the function of money as unit of account, instead of means of payment to facilitate trade. Institutionalist views on the origin of money actually focus on money's role as standard of value as its first and main function, including scholars such as Mitchel Innes (1913), Keynes (1976 [1930]) in the Treatise of Money, and Schumpeter (2014 [1970]). A unit of account or standard of value, as it is referred indistinctively, enables an abstraction from the objects on sale and the relationship of the traders. With a slightly different reasoning, Schumpeter (2006 [1954]) underlined the anonymity of money as a breakthrough in its evolution. For example, Ingham (2002: 36) claims that "for very lengthy periods, societies were able to trade without generally accepted means of payment but it is inconceivable that an economy spanning a large number of traders and tradable objects can exist without a generally accepted unit of account". The experience of the vendors in this research indicates that a standard of value is critical for any trade, even if the numbers of traders and tradable objects are small. A unit of account hence strengthens social cohesion in small groups by increasing the transparency and the fairness of trade.

In the present case study, the supporting group and some vendors thought that the design of a currency system for a small weekend market also entailed a number of possible complications. An alternative offered to the vendors was to use a basic commodity that could serve as unit of account and could be easily fractioned in small quantities, like cigarettes, pencils, or candies, but these were discarded for various reasons. The vendors questioned, for example, "Who will buy so many of them if we already lack money?" "What do we do with so many of them after we finish trading? Nobody needs them". "Those things are too small and we are not interested in them but in getting Christmas presents". The sentiment that "money is what we are used to, we understand it, money is better". After the second meeting, the entrepreneurs decided that they wanted a currency that could be used for a day only among their closed network to measure prices and facilitate trade: no barter and no commodity as a general equivalent, but scrip.

\section{Institutions, rules, and habits}

The usage of local and informal means of payment is not an anomaly any more. Complementary currency systems (CCS) are networks in which trade is performed with unofficial and local means of payment. They are becoming more disseminated 
around the world with a total over 1500 initiatives (Seyfang and Longhurst 2013). Researchers have approached them as schemes within the social and solidarity economy (Amin et al. 2002; Pacione 1997), which is understood as part of the substantive economy (Polanyi 1992). Social and solidarity economy initiatives are characterised as the activities that aim at the reproduction of life as opposed to the maximisation of profit and are normally organised collectively (Fonteneau et al. 2010). Moulaert and Ailenei (2005: 2038) emphasise that social and solidarity economy initiatives create "new values and institutions" and "generate institutional innovation" (Moulaert and Nussbaumer 2005: 2073). The authors claim that initiatives in the social economy multiply when mechanisms within the regular economy falter, but the theoretical foundations of their research programme are still in need of further development, and for example, there is minimal reflection on the kind of "institutional innovation" that is being referred to. A secondary aim of this research is to offer some reflections on the nature of the institutional innovation within the social and solidarity economy.

Institutions shape human behaviour and provide structure in society including critical mechanisms for decision-making. While central to human societies, there is still little consensus on a common definition of institutions or how to do institutional analysis (Hollingsworth 2000). Several academic disciplines have developed approaches to discussing and examining institutions, but there has been limited collaborative cross-learning among disciplines such as economics, sociology, history, and political science (e.g. North 1990; Williamson 1985; Hodgson 1989, 1998, 1999, 2003, 2006; Ostrom 1990; Campbell et al. 1991; Campbell 1993; Powell and Di Maggio 1991; Hall and Taylor 1996; Chang 2002). Despite such variation, institutions are always defined as social structures to broadly indicate their predictability (Wells 1970). Social structures are the social elements that give stability and meaning to human action (Crespi 1992), while other authors emphasise that they are "a set of enduring connections that give a sense of a whole" and not any random set of connections (Thompson 2018: 57).

Within the universe of social structures, institutions are the particular type that refers to the "socially embedded systems of rules" according to the classical definition of Geoffrey Hodgson (2006: 2). The first element in this definition is the characteristic of being "socially embedded", which means that institutions reflect the beliefs, values, and specific cultural contexts. The second basic element in the definition of institutions underlines the normative content in the rules that compose them which entails the possibility of sanctions when there is no compliance. Hodgson further defined rules as "an injunction or disposition" that guides human behaviour and have the specific logic format "in circumstances $X$, do $Y$ " (Hodgson 2006: 3 ). That means that while nature makes various actions possible in circumstances $\mathrm{X}$, society indicates that one specific action $Y$ is the acceptable one in a particular cultural setting, time and place. Rules are "considered, acknowledged, or followed without much thought" (Hodgson 2006: 4), so they are like "ideas inside the mind" that both constrain and enable human action (Hodgson 2004: 424). Within sociology, Max Weber similarly reasoned that 'some rules are followed without any subjective formulation in thought of the rule' (Weber 1978): 105). Institutions hence 
"create stable expectations of the behaviour of others" (Hodgson 2004: 425) and promote social order.

While institutions exist in the social arena and are external to individuals, they also exist in individuals' minds. This could appear contradictory: how can institutions exist at the same time in the different ontological levels of a society and an agent? This ontological problem is sorted by drawing on the concept of habit as bridge between the collective and individual levels. Veblen (2004/1919) described the dialectic relation between agent and structure as distinct entities that are connected by habits in circles of mutual interaction and interdependence. Habits are "dispositions to engage in previously adopted behaviour" when an agent is exposed to similar stimuli or contexts (Hodgson 2003: 556). Dewey (1922) connected habits to institutions by reasoning that institutions reflect on and shape individuals' habits in people's minds (Dewey 1922). Individuals' shared habits promote the production and reproduction of institutions at the social level and may guide individuals into repeating the action. By repeating it, individuals may reinforce the appropriateness of their own habits and attach them meaning by embedding them in a social system of values or beliefs, so these shared habits may become institutionalised after a period of time. Therefore, while agents and institutions exist at different ontological levels, the causal relationship from individuals' habits to institutions and vice versa follows a bidirectional effect of interdependence and interaction, as described by Veblen in The vested interests and the common man.

Such a double causality was further developed in recent scholarly work and termed reconstitutive upward effect (Hodgson 2002, 2007) to describe the process by which elements of a lower ontological level, such as agents, affect elements of a higher ontological level, such as institutions. The inverse directionality was termed reconstitutive downward effect, and refers to institutions informing and contributing to the formation of habits and individuals' minds. That social process defines "what has meaning and what actions are possible" in experimentation (Powell and Di Maggio 1991: 9). Hodgson (1998) depicted the interaction between agents and institutions as a stable loop that feeds unto itself (Fig. 1). Institutions inform individuals on what actions $Y$ are acceptable in circumstances $X$ and individuals are inclined to follow and act in that way. The repetition of the action indicated by the social institution, in turn, shapes individuals' habits and reinforces the acceptance of the institution and its embeddedness in a particular social setting. The possibility that agents may deviate from these dispositions exists, but their choice does not mean that the

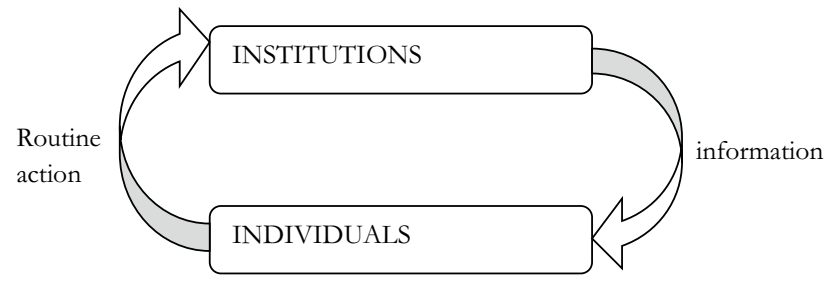

Fig. 1 Institutionalist action-information loop Source: Hodgson (1998: 176) 
inclination ceases to exist or that their deviation will not be perceived as an abnormality that could lead to sanctions.

This depiction effectively explains the stability of institutions, but does not address evolution. In other words, the narrative of routine action in a closed loop emphasises continuity and permanence in a manner that clearly differs from the dynamism and innovation of social life. Social economy scholars (Moulaert and Nussbaumer 2005; Moulaert and Ailenei 2005), in comparison, look at processes of institutional change as those that binds individuals in communities, associations, and other similar collectives that share and co-create values, interests and intentions, support learning, and generate acceptability for new rules of action. The next section builds on the notion that institutions organise social interaction and facilitate collective action at the same time, as collective action is one of the basis to create and change institutions. The concepts of habit, rules, institutions, and cultural values are combined to explain institutional innovation in the social and solidarity economy based on the case of complementary currencies.

\section{Collective action and bricolage}

In the case study of the vendors' marketplace, the creation of a complementary currency implied configuring an institution for a particular group and, in turn, agreeing on various rules. The rules were multiple and included among other aspects the division of labour to manage the currency, how much money to create, how to inject it in the system, how much to distribute to each participant, what the scrip should look like and what name it should have, what denominations to use, and the key question of whether to use collateral in a treasury. The vendors' currency can be considered an institutional innovation, because it was socially constructed, was not in the minds of particular individuals, led their actions according to a set of rules, and created mutual expectations of acceptable behaviour. If a vendor who was not part of the process of institutional design (i.e., the negotiations and agreements) had joined at a later stage, she would have found a running social order and would have been compelled to act according to the accepted rules of action. The size of the population to which an institution applies is not relevant as long as an institution is collective, socially embedded in a set of values and beliefs, a system of rules that guide acceptable social action and the various traits that define an institution as such, as mentioned in Sect. 3. The scale of the population to which an institution applies does not affect its conceptualisation as such, as was similarly argued by Lewis (2008), Swanke (2004) and others.

The creation of a currency system appears as a highly complex initiative but the process of institutional design was facilitated by emulating the characteristics of both the formal monetary system and its subsequent modifications during the configuration of the Redes de Trueque and other community currency systems in Argentina. In other words, the socially embedded system of rules in the Argentina's monetary system contains a generalised acceptance for complementary currencies from various issuers. Monetary plurality, defined as the simultaneous existence of more than one type of currency at the same time and in a specific territory, was a long 
accepted institution among the micro-entrepreneurs that participated in the experience. As argued by Swanke (2004: 89), the design of any new currency system does not happen in a vacuum but in the shadow of long-held shared habits and experiences. In the case study, the vendors aimed to adapt "common knowledge" (Lewis $1967\{2008\}$ ) on monetary plurality to their particular context. Still, institutional innovation such as the vendors' marketplace currency reflects a double process of adapting existing rules to the context and designing new ones through collective discussions.

Habit, in Veblen's conceptualisation, accounts for actors' preference to behave in the ways they are comfortable with and reproduces social structures. Other authors, such as Campbell (1997), suggested that most changes in existing institutions unfold in a process of delimited selection permitted by the existing institutions. For the micro-entrepreneurs in the case study, the convenience of using a currency to trade their goods was part of that common knowledge that limited further reflection on whether it was the option that minimised transaction costs, for instance. One microentrepreneur stated that: "Everyone knows how to trade with money, why look for something else?" and another one said that, "money is what everyone knows". They were inclined to design their currency "to be like any other currency". The fact that script is the most accepted means of payment to facilitate trade seemed to make the search for alternatives unnecessary. In comparison, complementary currencies are considerably less acceptable in many countries in the world, and in some, they are even illegal (Gómez and Dini 2016). They clash with the established institutions of the monetary system, in which a basic rule is the state's monopoly over the issuance of means of payment. However, in the context of Argentina, complementary currencies were common and the vendors in the case study had already acquired that habit, which deviates from the international institution of money. None of the vendors in the scheme made an issue out of the legality or illegality of making their own local currency.

Institutional change has been characterised in economic sociology as path dependent and isomorphic (DiMaggio and Powell 1983; Friedland and Alford 1991). The concept of path dependence refers to the historical dominance of institutional design, which implies the convenience of existing arrangements and limits the options and the flexibility in the construction of new institutions. Yet, the reproduction of existing institutions may also be due to a lack of imagination of alternatives (Friedland and Alford 1991) or a simple "source of inertia" (Dosi 1995: 12). DiMaggio and Powell (1983) build upon the early conceptualisation of "isomorphism" introduced by Meyer and Rowan (1977) to refer to the homogenization of organisational forms that induces communities to accommodate to the outside world. They highlight three types of isomorphic influences: coercive pressures from political pressures and legitimacy, mimetic pressures from the tendency to reproduce standard responses to uncertainty, and normative pressures related to a desire for professionalism and modernity.

Institutional change implies finding new and acceptable ways of acting and this search happens under the limits of isomorphism (imitating similar existing institutions) and the constraints of path dependence that give resilience to the existing institutions of money that define what is possible and what is not. Schofield, Greif 
and Kingston (2011) noted that past institutional elements are "the raw material on which new institutions are based", while others authors (Sugden 1989) argued that agents engaged in institutional change coordinate their strategies to achieve it but "generally adopt rules which are analogous to rules with which they are already familiar". In other words, habits embed the inclinations and preferences that guide the change process. Along this line of thinking, Campbell (2004) argued that actors often create new institutions through a process of "bricolage": recombining elements in their institutional repertoire to deal with new situations (Gomez 2008). As a result, new institutions are often adaptations of the pre-existent ones. Moreover, Schofield, Greif and Kingston (2011) and Greif et al. (1994) argued that organisations inherited from the past and cultural beliefs shape the choices among alternative institutions, among other reasons, because the interaction with specific networks determines, whose identity is known to whom, and where information flows, while cultural beliefs coordinate expectations.

In the vendors' marketplace, they belong to the disenfranchised middle class, their low sales, the absence of attainable alternatives, and the previous positive experience with the Redes de Trueque provided fertile ground to create a new type of money, one that would circulate within a specific group for a day and which relied precisely on collective action to define its rules and modify individuals' habits. The collective of vendors was critical to provide information, facilitate learning, and identify experiences to imitate. It also shaped intentions and interests, which affected the reasoning to search for solutions. Therefore, habit provided the cognitive means by which information was sought and interpreted, while it defined what experimentation was possible and supported its institutionalisation as a new rule of action. The micro-entrepreneurs ventured in a "bricolage process" relying on high degrees of trust and social cohesion to sustain collective action, on the one hand, and their own habits regarding the existing Argentine monetary institutions (national and complementary) as "the raw material" on which their own currency would be based. However, the complications of creating a currency became evident as the discussions on its design began and it took another two long meetings in consecutive Saturdays. The adaptation of the existing rules entailed looking into a large number of matters that strained social cohesion. For example, on the issue of the vouchers' denomination, nobody actually knew what the right numbers to write on each type of notes was. The support group decided to follow an iterative process. An assistant asked if anyone had any goods that required 50 cents, and there were none. Then, she asked the same question for $\$ 1$ and there was one, so they decided to make $\$ 1$ the note of smallest denomination. At that point, another participant said that she had some pastries to sell for \$1.50, how should she do it? Another participant suggested that she should sell two pastries for three, and she accepted. Eventually, three entrepreneurs took the task of discussing how many notes to make of each denomination and they took almost one hour to decide.

Another issue was the name; the currency eventually names its unit of account "points" to avoid transferring the name "peso" of the official currency. The familiarity with the rules that had to be recreated was only partially helpful, somehow limiting the usefulness of the concept of isomorphism, which does not explain analytically what aspects are imitated and which ones are adapted. Later, it was agreed 
to use the same prices as in regular money, hence keeping the parity of one peso to one point. In turn, it was decided that the amount of points to create. The assistant assessed the sales that they had per day and estimated that it would be enough with 20 points per vendor. However, some vendors thought that it would be better to make 30 points to facilitate more trade, although the support team explained that it would not necessarily have that effect.

A question that kept coming in every discussion with them during the adaptation of institutions was: "what do we want to achieve with this rule? What is this rule for, what is it supposed to imply for the scheme?" In the process of bricolage, every decision implied reflection and the lengthy bargaining between applying existing rules of the institution of money (national and complementary) as the vendors knew it and designing new rules for their own local currency. The creation of a treasury illustrated the process of bricolage between old and new rules. The goal in organising a "treasury" was to avoid that anyone would leave the market feeling disappointed or that the trade had been unfair. The first idea discussed was to deposit pesos in official currency, so at the end of the scheme, if anyone was unable to find anything to buy, they could at least return home with some money. The option was rejected by those who said that they did not have any amount of money, so they could not afford it. The second idea discussed was to leave as deposit a stock of goods equivalent to the points each vendor would obtain and these goods would be placed on sale at the end of the day, as the currency was removed from circulation. It appeared as a good idea, but the support team explained that the risk was that the first ones to buy from the stocks in the treasury would take the most interesting products and the last ones would have less choice. The decision was made that the vendors would have the right to recover their own stocks first and subsequent bartering would follow. The assistant was chosen to act as treasurer and keep records of stocks. This decision seemed to satisfy the vendors, mixing the habit of having a treasurer as recipient of trust and collateral with their own rule to keep a deposit in kind and some special provisions to avoid disappointment. After the distribution of the notes, trade began and this went as in any other market. The actual trade happened on the second Saturday of December 2012.

\section{A model of institutional bricolage}

When institutions are established for a long time, no reflection on the content of the institutions follows action and a routine loop is fixed, as shown already in the representation of Fig. 1. Rules had the logical form "in circumstances $X$ do Y". They resemble points of equilibria and institutions would only be revised if there are "exogenous shocks to displace the state from the equilibrium" (Hashimoto and Nishibe 2017: 3). However, in the case study, there was no external shock that induced institutional innovation, but the desire to improve a situation perceived as unsatisfactory. The routine situation of selling goods in a weekend market with regular money as means of payment was not enabling vendors' to buy Christmas presents. They thought of making their own currency to facilitate trade, as it had been done in the past with the complementary currencies in Argentina. 
To understand such an institutional innovation, typical of the social and solidarity economy initiatives, the reasoning in Fig. 1 needs to be modified to incorporate an instance of assessment of the effective outcomes of the action and the extent to which these outcomes are aligned with the expectations derived from the institutions in equilibrium. Aoki (2007: 3) refers to a "consequence function" that specifies "particular (physical) consequences of concern to some or all the agents [contingent on the state of nature]." The logical form of the rules changes to include the consequence function that relates $Y$ and its outcomes, $Z$. As a result, the form of a rule should be written as "in circumstances $X$ do $Y$ and expect $Z$ ", so the expectation to obtain $Z$ becomes part of the rule to do $Y$ in circumstances $X$. Although actions may be performed without premeditation and out of non-reflexive rule-following habit, the repeated occurrence of $Z$ continues to provide motivation to follow the rule. Moreover, it gives a way of assessing the course of action and the validity of the rule within a specific context. The failure to obtain $Z$ may trigger a reflexive response to revise the rule and evolution can also be explained in the absence of external shocks.

In addition, situations $X$ are rarely completely invariable or identical, and sometimes, they are completely or partially new, which may happen when changes in the environment make rule-following inadequate to achieve particular objectives. Situations in which $Z$ fails to happen may be attributed to new circumstances (a changed or unknown $\mathrm{X}$ ), so $Y$ is performed, but $Z$ fails to happen. Another possibility is that the social values that embedded institutions have changed and $Y$ is no longer acceptable in situation $X$. Agents would be unable to find accepted dispositions for some situations $X$, so a response $Y$ needs to be formulated and this $Y$ needs to be socially acceptable in relation with the rest of the other values and institutions in a social system.

The reasoning is represented in Fig. 2. In comparison with Fig. 1, agents in Fig. 2 engage in finding a new solution. If it is a modified situation, the logical form is: In circumstances $X^{\prime}$, do $Y^{\prime}$ to obtain an objective $Z^{\prime}$, which represents an entirely new rule in which rational and instrumental agents innovate based on the information that they have available. If it is a known situation $X$ in which the action $Y$ and/ or the outcome $Z$ have become unacceptable (dislocated from the social values and beliefs), a new action $Y$ needs to appear, so that in circumstances $X$, do $Y^{\prime}$ to obtain an acceptable outcome. Schofield, Greif and Kingston (2011) refer to this situation as an "institutional disequilibrium" which results when an institution ceases to be an accepted alignment between beliefs, cultural values, and experiences, on one hand, and the courses of action, expectations, and outcomes, on the other. This may occur because of exogenous shocks, but it may also happen because of endogenous changes in the understanding of the world and exposure to collective action that creates new habits. That is, agents learn and change over time, so they may ultimately make the institutions obsolete (Greif and Laitin 2004).

In Fig. 2, the information-action loop of Fig. 1-is now reconfigured into three loops. In the first loop at the top, agents respond to a routine situation $X$ with a routine action Y. It is routine action already experienced as acceptable and leading to an expected outcome $Z$. There is no change in this loop, so it a reproduction loop by which institutions and agents remain the same. In the case study, it would be the Argentine institution of money combining national and complementary currencies. 

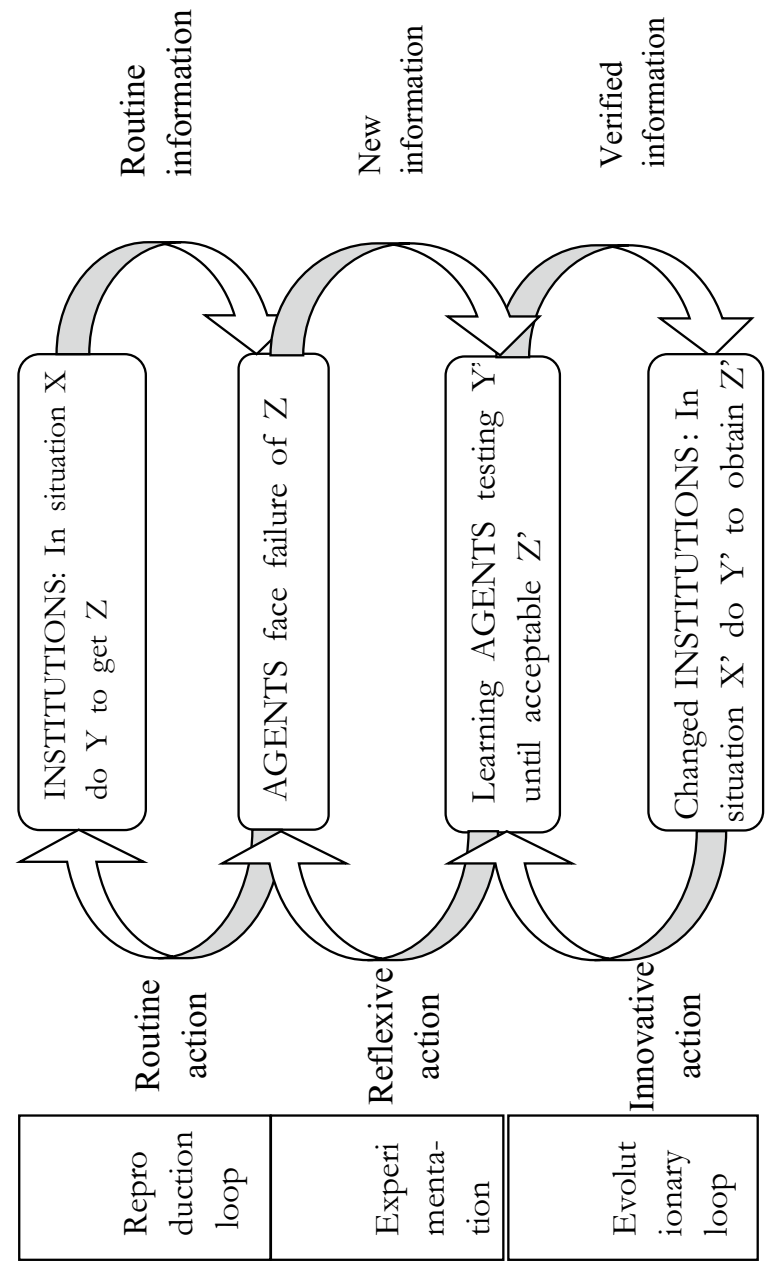

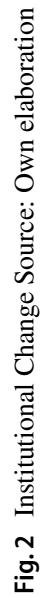


However, for the vendors, $Z$ failed to occur and they could not achieve their goal of affording Christmas presents.

The model is hence reconfigured to include a second loop in which agents experiment together with new actions $Y^{\prime}$ based on their collective action. Insufficient information is available to define an appropriate course of action and the vendors seek out new data, test alternatives, resort to reflective discussions, and invite experts. Learning takes place, while agents test and reflect on alternative courses of action that the other institutions and values in the social system indicate as acceptable. The existent institutions inform what experimentation is possible, so the reproduction loop is still present with institutions that enable and persuade learning agents. This type of reflection is termed the experimentation loop (middle). Reflexive action takes over routine as the agents seek to innovate collectively and create interpretation of the situation $X$ and the assessment of the results $Z$. In the case study, it is represented by the discussions and contacts with the support team. The responses $Y^{\prime}$ are tested and perceived as suitable or unsuitable to achieve acceptable results $Z^{\prime}$. When an agreement is reached, the action $Y$ can be repeated for a situation $X^{\prime}$ and it will become the accepted course of action. This conceptualisation explains the process that gives birth to new institutions, although in rigour, they are only partially new, because they are based and depend on pre-existent institutions as their raw material. They do present an innovation in the sense that they are a new course of action and an evolution in the sense that they may become a new institution that helps agents to reduce the complexity of social life. Aoki considers that once an institution acquires a linguistic or symbolic representation recognised and reproduced by other agents, it may be regarded to have existence as an objective reality, which implies that it has evolved into an institutional fact (Searle 1995).

\section{Conclusions}

Back to the question posed in this article, why do people want a currency? The model presented above suggests that people want currency because of the engrained habits of thought that guide their actions. The rule is: 'To buy, use money to obtain your goods', and its mirror rule is 'to sell, use money that cancels the debt for your goods'. There need not be a reflexive deliberation on behalf of the people in general on the qualities of money and there need not be a political statement in terms of either contesting the use of money in the capitalist system or endorsing it as the most efficient solution to trade. Money is the means of payment which agents have always identified to mediate payments. It would seem rather exotic that a group of impoverished vendors would make their own currency for a day. Given the monetary history of Argentina, it is not so exotic. Economic agents have been used to various manipulations with the currency, both by the government as by other agents. Hundreds of community currencies circulated in Argentina between 1995 and 2006, so the fact that a local group of vendors designs its own currency to facilitate payments and measure prices is still within the acceptable limits of the institutions in place, as noted elsewhere (Gómez and Dini 2016). 
Should all open markets have their own currency? Is this the best solution for this type of micro-entrepreneurs with low sales? Jens Beckert (2003) provides a theory of action in economic contexts of complexity and novelty. Uncertainty not only makes it impossible to identify a "best" solution but to link the causal relationship between means (strategies) and outcomes. Every situation has several readings judged as adequate by the actors. Other open markets in squares have not developed this solution. In turn, decisions depend on joint interpretations of the situation within specific collective groups. This is where inter-subjectivity and networks play a role, since orientations, perceptions of values, and beliefs are formed with the expectations brought on them by the social surrounding, where they are embedded (Granovetter 1992). Other groups of traders have not thought about breaking with the use of regular money in this way or may not have the sufficient social cohesion to make it possible. The vendors in the case study acted in a crisis that was resolved in a process of innovation by experimentation in which possible future courses of action were considered along with the strategies to reach them. Experimentation represented a creative achievement on the part of the actors that demanded imagination and judgement, taking a reflexive distance from habit. The term "acceptable solution" means that it need not be "optimal" but one that resolves a situation. If actors succeed in framing a new mode of action and repeat it in similar situations, then they may repeat it and "something new enters the world" (Joas 1996: 128). Aoki (2007: 11) defined the process as an "equilibrium displacement and its reconstruction".

If the new rule in situation $X^{\prime}$ do $Y$ to obtain $Z^{\prime}$ actually institutionalises, there may be two consequences. First, the experience changes agents and their habits, and it is repeated in every Christmas. A new possibility with complementary currencies has become acceptable in their context. We may contrast with the effects in the opposite extreme, in which governments create new rules with legal status and statebacking to induce new courses of action $Y^{\prime}$ in circumstances $X$ but the absence of complementary institutions, supporting competences and general acceptance of the rule will not change habits in agents' minds and they will not institutionalise (Aoki and Hayami 2001: 267-269).

Second, in a process of isomorphism, vendors' currencies become part of the possible solutions known to society, so the institution may be imitated by others in search for solutions to similar situations $X$. It institutionalises in such a way that the representation in Fig. 1 can explain the actions of these other agents. In that sense, new "common knowledge" was generated, which means that evolution occurrednew institutions have been created expanding the possible courses of action $Y^{\prime}$ to obtain desirable $Z^{\prime}$. Schofield, Greif and Kingston (2011) similarly conceptualise that a social situation is "institutionalised" when it "motivates each individual to follow a regularity of behaviour in that social situation and to act in a manner contributing to the perpetuation of that structure". For an institution to be perpetuated, the authors continue, "its constituent elements must be (1) confirmed (not refuted or eroded) by observed outcomes (2) reinforced by those outcomes (in the sense that its ability to be self-enforcing does not decline over time) and (3) inter-temporally regenerated by being transmitted to newcomers." 
With differences of focus and emphasis, the views presented in this article are consistent with other socio-economic evolutionary approaches, such as those discussed Aoki and Hayami (2001) and by Hashimoto and Nishibe (2017) in this Journal. Cross fertilisation with concepts of evolutionary economics would be an interesting project for future research that could not be part of this article on account of space and coherence.

Acknowledgements The author is thankful to Maria Adela Plasencia at the Universidad de Lujan, Argentina for making the research possible with contacts and data.

Open Access This article is distributed under the terms of the Creative Commons Attribution 4.0 International License (http://creativecommons.org/licenses/by/4.0/), which permits unrestricted use, distribution, and reproduction in any medium, provided you give appropriate credit to the original author(s) and the source, provide a link to the Creative Commons license, and indicate if changes were made.

\section{References}

Amin A, Cameron A, Hudson R (2002) Placing the social economy. Routledge, London Aoki M (2007) Endogenizing institutions and institutional changes. J Inst Econ 3:1-31

Aoki M, Hayami Y (2001) Communities and markets in economic development. Oxford University Press, Oxford

Beckert J (2003) Economic sociology and embeddedness: how shall we conceptualize economic action? J Econ Issue 37:769

Campbell D (1993) Evolutionary epistemology. In: Radnitzky G, Barthley W (eds) Evolutionary epistemology, rationality, and the sociology of knowledge. Open Court, La Salle, pp 47-89

Campbell JL (1997) Mechanisms of evolutionary change in economics governance: interaction, interpretation and bricolage. In: Magnusson L, Ottosson J (eds) Evolutionary economics and path dependence. Edward Elgar, Cheltenham

Campbell JL (2004) Institutional change and globalization. Princeton University Press, Princeton

Campbell J, Hollingsworth JR, Lindberg L (1991) Governance of the American economy. Cambridge University Press, Cambridge

Chang H-J (2002) Breaking the mould: an institutionalist political economy alternative to the neo-liberal theory of the market and the state. Camb J Econ 26:539-559

Cleaver F (2002) Reinventing institutions: bricolage and the social embeddedness of natural resource management. Eur J Dev Res 12:11-30

Crespi F (1992) Social action and power. Blackwell, Texas

Dewey J (1922) Human nature and conduct: An introduction to social psychology,1st edn. Holt, New York

DiMaggio P, Powell W (1983) The iron cage revisited: institutional isomorphism and collective rationality in organizational fields. Am Sociol Rev 48:147-160

Dosi G (1995) Hierarchies, markets and power: some foundational issues on the nature of contemporary economic organizations. Ind Corp Chang 4(1):1-19

Fonteneau B, Neamtan N, Wanyama F et al (2010) The Reader 2010. "Social and Solidarity Economy: Building a Common Understanding. In: Academy SaSE (ed), International Training Centre of the ILO

Friedland R, Alford R (1991) Bringing society back in: symbols, practices and institutional contradictions. In: Powell W, DiMaggio P (eds) The new institutionalism in organizational analysis. University of Chicago Press, Chicago, pp 232-263

Gomez GM (2008) Making markets. The institutional rise and decline of the Argentine Red de Trueque. The Hague: Institute of Social Studies, 333

Gomez GM (2009) Argentina's parallel currency: the economy of the poor. Pickering \& Chatto, London

Gomez GM (2010) What was the deal for the participants of the Argentine local currency systems, the Redes de Trueque? Environ Plan A 42:1669-1685 
Gómez GM, Dini P (2016) Making sense of a crank case: monetary diversity in Argentina (1999-2003). Camb J Econ 40:1421-1437

Granovetter M (1992) Economic institutions as social constructions: a framework for analysis. Acta Sociologica 35:3-11

Greif A, Laitin DD (2004) A theory of endogenous institutional change. Am Polit Sci Rev 98:633-652

Greif A, Kingston C (2011) Institutions: rules or equilibria? In: Schofield N, Caballero G, Greif A, et al. (eds) Political economy of institutions, democracy and voting. Springer, Berlin, Heidelberg, pp $13-43$

Greif A, Milgrom P, Weingast B (1994) Coordination, commitment and enforcement: the case of the merchant guild. J Polit Econ 102:745-776

Hall P, Taylor R (1996) Political science and the three new Institutionalisms. Polit Stud 44:936-958

Hashimoto T, Nishibe M (2017) Theoretical model of Institutional ecosystems and its economic implications. Evolut Inst Econ Rev 14:1-27

Hodgson G (1989) Economics and Institutions: a manifesto for a modern institutional economics. Polity Press, Cambridge

Hodgson G (1998) The approach of Institutional Economics. J Econ Lit 36:166-192

Hodgson G (1999) Evolution and institutions: on evolutionary economics and the evolution of economics. Edward Elgar, Cheltenham

Hodgson G (2002) Reconstitutive Downward Causation: social structure and the development of institutional agency. In: Fullbrook E (ed) Intersubjectivity in economics: agents and structures. Routledge, London, pp 159-180

Hodgson G (2003) The hidden persuaders: institutions and individuals in economic theory. Camb J Econ $27: 159-175$

Hodgson G (2004) The evolution of institutional economics: agency, structure and Darwinism in American institutionalism. Routledge, London

Hodgson G (2006) What are institutions? J Econ Issue 40:1-25

Hodgson G (2007) Institutions and Individuals: interaction and evolution. Org Stud 28:95-111

Hollingsworth JR (2000) Doing institutional analysis: implications for the study of innovations. Rev Int Pol Econ 7:595-644

Ingham G (2002) New monetary spaces? In: OECD (ed) The future of money. Paris: OECD, pp 123-145

Innes AM (1913) What is money? Bank Law J pp 377-408

Jevons WS (1875) Money and the mechanism of exchange. Elibron Classics, London

Joas H (1996) The creativity of action. Chicago University Press, Chicago

Keynes JM (1976 [1930]) A treatise on Money. Harcourt, Brace and Co, New York

Krabbe R (2015) Building trust: exploring the role of community exchange and reputation. Int J Commun Curr Res 19:62-71

Levi Strauss C (1962) Savage mind. University of Chicago, Chicago

Lewis D (2008\{1967\}) Convention: a philosophical study. Wiley, Amsterdam

Melitz J (1974) Primitive and modern money. Addison Wesley, Reading

Menger K (1892) On the origin of money. Econ J 2:239-255

Meyer J, Rowan B (1977) Institutionalised organisations: formal structure as myth and ceremony. Am J Sociol 83:340-363

Moulaert F, Ailenei O (2005) Social economy, third sector and solidarity relations: a conceptual synthesis from history to present. Urban Stud 42:2037-2053

Moulaert F, Nussbaumer J (2005) Defining the social economy and its governance at the neighbourhood level: a methodological reflection. Urban Stud 42:2071-2088

North D (1990) Institutions, institutional change and economic performance. Cambridge University Press, Cambridge

Ostrom E (1990) Governing the commons: the evolution of institutions for collective action. Cambridge University Press, Cambridge

Pacione M (1997) Local exchange trading systems as a response to the globalisation of capitalism. Urban Stud 34:1179-1199

Peacock MS (2012) The political economy of homeric society and the origins of money. Camb J Econ 30:47-65

Polanyi K (1992) The economy as Instituted Process. In: Granovetter M, Swedberg R (eds) The sociology of economic life. Westview Press, Boulder, pp 29-52

Powell W, Di Maggio P (1991) The new institutionalism in organisational analysis. Chicago University Press, Chicago 
Samuelson P (1967) Economics; an introductory analysis, McGraw-Hill, New York

Schumpeter JA (2006 [1954]) History of economic analysis, with an introduction by Mark Pelman. Routledge, London

Schumpeter JA (2014 [1970]) Treatise on money. Wordbridge Publishing, Aalten

Searle JR (1995) The construction of social reality. Simon and Schuster, New York

Searle JR (2005) What is an institution? J Inst Econ 1:1-22

Seyfang G, Longhurst N (2013) Growing green money? Mapping community currencies for sustainable development. Ecol Econ 86:65-77

Smith A. (1991 [1776]) The wealth of Nations. Everyman's Library, London

Sugden R (1989) Spontaneous order. J Econ Perspect 3:85-97

Swanke T (2005) Understanding the implications of money being a social convention. In: Wray R, Forstater M (eds) Contemporary post Keynesian analysis. Edward Elgar Publishing, Cheltenham, pp 84-99

Thompson N (2018) Applied Sociology. Routledge, London

Veblen T (1899) The theory of the leisure class, Champaign, Ill. [P.O. Box 2782, Champaign 61825]: Project Gutenberg

Veblen T (2004/1919) The vested interests and the common man. Kessinger Publishings, Montana

Weber M (1978) Max Weber. Selections in Translations. In: Runciman WG (ed) Cambridge, Cambridge University Press

Wells A (1970) Social Institutions. Heinemann, London

Williamson O (1985) The economic institutions of capitalism. Firms, Markets and relational contracting. The Free Press and Macmillan, New York 